\title{
Da fronteira da invisibilidade para o discurso da legalidade: a Umbanda como patrimônio cultural de natureza imaterial
}

\author{
De la frontera de la invisibilidad al discurso de la legalidad: La Umbanda \\ como patrimonio cultural inmaterial
}

\author{
From the frontier of invisibility to the discourse of legality: Umbanda as \\ an intangible cultural heritage
}

Gracielle Rafaela Campos Baldiotti ${ }^{1}$

Terezinha Richartz ${ }^{2}$

\begin{abstract}
Resumo
Embora o Decreto $\mathrm{n}^{\circ} 42557$ de 2016 tenha estabelecido a Umbanda como patrimônio cultural de natureza imaterial do Rio de Janeiro, e ainda determinado, a criação do cadastro dos terreiros umbandistas, ela é colocada à margem pelo fato de muitos não acreditarem se tratar de uma religião, acarretando, então, uma intolerância religiosa desvendada em, por exemplo, destruição de templos e objetos que compõem as cerimônias, preconceito sofrido pelos praticantes e desrespeito aos rituais. Para tanto, objetiva-se no presente, resgatar memórias da religião umbandista, esquecidas ou reprimidas por valores hegemônicos da Igreja Católica, além de trazer conhecimento/informações face à valorização de expressão religiosa genuinamente brasileira, o que poderá garantir respeito e reconhecimento pela sua história, evitando assim, que essa não seja perdida/esquecida no tempo, devido ao fenecimento dos mais antigos que carregam suas vivências. Nesse contexto, trata-se de um estudo bibliográfico, que guiado por embasamento teórico, proporciona a elaboração de pressupostos variantes da abordagem proposta. Ao considerar a Umbanda como patrimônio cultural de natureza imaterial, o Estado, através do discurso da legalidade, cria condições para o levantamento de todos os terreiros existentes no Rio de Janeiro, e com ele, toda a tradição oral, juntamente com elementos materiais e imateriais que dão vida ao sincretismo experienciado em cada terreiro.
\end{abstract}

Palavras-Chave: Umbanda. Patrimônio cultural imaterial. Religião. Discriminação. Reconhecimento.

\section{Resumen}

Si bien el Decreto no 42557 de 2016 estableció la Umbanda como patrimonio cultural inmaterial de Río de Janeiro, y aún determinó, la creación del registro de Terreiros de Umbanda, se deja de lado por el hecho de que muchos no creen que sea una religión., provocando, entonces, una intolerancia religiosa develada, por ejemplo, en la destrucción de templos y objetos que componen las ceremonias, los prejuicios que sufren los practicantes y la falta de respeto a los rituales. Para ello, el objetivo del presente es rescatar recuerdos de la religión Umbanda, olvidados o reprimidos por los valores hegemónicos de la Iglesia Católica, además de aportar conocimientos / información sobre la valoración de la expresión religiosa genuinamente brasileña, que pueda garantizar el respeto y reconocimiento de su historia. , evitando así que no se pierda / olvide en el tiempo, por la desaparición de los mayores que cargan con sus vivencias. En este contexto, se trata de un estudio bibliográfico, que guiado por una base teórica, proporciona la elaboración de supuestos que varían del enfoque propuesto. Al considerar la

\footnotetext{
${ }^{1}$ Mestra em Letras - Linguagem, Cultura e Discurso; Universidade Vale do Rio Verde; Três Corações, Minas Gerais, Brasil; graciellebaldiotti@ hotmail.com.

${ }^{2}$ Doutora em Ciências Sociais (PUC/SP); Professora da Universidade Vale do Rio Verde; Três Corações, Minas Gerais, Brasil; unipampacassia@gmail.com.
} 
Umbanda como patrimonio cultural inmaterial, el Estado, a través del discurso de la legalidad, crea condiciones para el relevamiento de todos los terreiros existentes en Río de Janeiro, y con ella, toda la tradición oral, junto con elementos materiales e inmateriales. que dan vida al sincretismo vivido en cada terreiro.

Palabras claves: Umbanda. Herencia cultural intangible. Religión. Discriminación. Reconocimiento.

\begin{abstract}
Although the Decree $n^{\circ} 42557$ of 2016 established Umbanda as an intangible cultural heritage of Rio de Janeiro, and still determined, the creation of the register of Umbanda terreiros, it is set aside by the fact that many do not believe that it is a religion, causing, then, a religious intolerance unveiled in, for example, destruction of temples and objects that make up the ceremonies, prejudice suffered by practitioners and disrespect to rituals. To this end, the objective is to recover memories of the Umbanda religion, forgotten or repressed by hegemonic values of the Catholic Church, in addition to bringing knowledge / information regarding the appreciation of genuinely Brazilian religious expression, which can guarantee respect and recognition for its history., thus avoiding that it is not lost / forgotten in time, due to the demise of the oldest who carry their experiences. In this context, it is a bibliographic study, which guided by a theoretical basis, provides the elaboration of assumptions that vary from the proposed approach. When considering Umbanda as an intangible cultural heritage, the State, through the discourse of legality, creates conditions for the survey of all the existing terreiros in Rio de Janeiro, and with it, the entire oral tradition, together with material and immaterial elements that give life to the syncretism experienced in each terreiro.
\end{abstract}

Keywords: Umbanda. Intangible cultural heritage. Religion. Discrimination. Recognition.

\title{
1. Introdução
}

Até a promulgação da Constituição de 1988, oficialmente, definia-se o Brasil como sendo um país católico, o que também pode ter contribuído para que a Umbanda fosse enxergada como preterida, à margem de crenças sociais por muitos e até mesmo pelo Estado. Sendo essencialmente oral e praticada por pessoas simples, reúne elementos de várias religiões, mas ainda assim, existe todo um preconceito ideológico para com ela, fazendo com que, por vezes, os meios de comunicação exibam notícias referentes a perseguições e depredações de templos umbandistas e afins. E é nesse viés que se objetiva discorrer sobre uma religião discriminada e, ao mesmo tempo, reconhecida como patrimônio cultural imaterial do Rio de Janeiro.

O que a torna patrimônio é, justamente, a reunião de tantos elementos culturais, sociais e religiosos oriundos do Candomblé, Catolicismo, Kardecismo e das tradições indígenas, visto que a caracteriza genuinamente brasileira e como sendo a religião de todos os povos, além de trazer a identidade dos negros escravizados como legado para as gerações mais jovens, desencadeando, então, o respeito por essa cultura tão rica que deve ser preservada. Nesse 
cenário, ao estabelecer a Umbanda como patrimônio cultural imaterial, o estado reconhece a importância dessa religião e resgata a sua memória.

\section{A Umbanda e o sincretismo religioso}

A Umbanda começou a ser difundida no Brasil por volta dos anos 1920 e 1930, quando kardecistas da classe média mesclavam suas práticas com elementos de tradição religiosa africana, com o catolicismo e as tradições dos indígenas. Assim, em sua gênese, a religião umbandista se constitui de elementos provenientes dessas religiões anteriormente mencionadas, o que suscita o seu sincretismo religioso da Umbanda como símbolo de elementos intocáveis de dada cultura, associada a tradições, crenças e práticas de grupos sociais.

O Brasil, nesta época, passa por um processo de miscigenação. "A Umbanda é criada num contexto de valorização do 'ser brasileiro'[...] com maior abertura às formas populares afro-brasileiras" (NASCIMENTO, 2010, p. 937). Esse sincretismo religioso, carrega em seu bojo, a origem do culto a entidades africanas, como por exemplo, a do "Preto Velho", que é o espírito dos negros escravizados, bem como, aos santos católicos e entidades que foram acrescentadas por influência kardecista. De acordo com Rosseto (2016),

As religiões que chegaram ao Brasil no período do comércio de escravos já não eram puras, mas se encontravam misturadas. Dentro dessa perspectiva, é importante observar que os negros não abandonaram a sua religião, mas se apropriaram de determinados aspectos do catolicismo, como forma de ocultar a sua crença africana. (ROSSETO, 2016, p. 12).

Em vista disso, percebe-se a Umbanda como uma mistura de crenças, além de apresentar seus terreiros como ponto de visitação por todo tipo de indivíduo, abertos a todos, que, de alguma forma, buscam socorro para dores da alma.

Após a Era Vargas, ela passa a ser reconhecida e deixa de ser perseguida, sendo vista como a primeira religião realmente brasileira. No entanto, segundo Prandi (2004, p. 4), ainda sofre preconceito nos dias de hoje, por ser fruto de sincretismo religioso.

De acordo com Castro, era de se esperar que as religiões de origem ou influência africana fossem extintas, por conta da dissolução dos grupos de negros libertos da escravidão. Mas o que se vê atualmente, é uma vasta gama de templos que, apesar de terem seus próprios rituais, ainda carregam muitos traços herdados dos africanos: 
Apesar de vestirem uma nova roupagem, as suas divindades, o seu objeto de adoração, permanece o mesmo. A sua associação com os santos católicos parecem se reunir em uma fusão de divindades criando assim uma manifestação cultural religiosa diferente daquelas iniciais. (CASTRO, 2013, p. 48).

Com o passar do tempo, ainda segundo Castro, “[...] de forma intencional ou não as diferentes formas de culturas ao se encontrarem vão se fundindo [...] e na medida em que vão se relacionando vão se modificando" (CASTRO, 2013, p. 49).

Esse fator pode ocorrer quando um indivíduo, ao buscar respostas para seus conflitos, entra em contato com outras religiões, experimentando e percebendo, então, em qual delas encontrará as respostas que almeja. O sincretismo também aí ocorre, pois, ao sair de uma religião para outra, o indivíduo carrega consigo traços e o que já desenvolveu nesse caminhar.

O Brasil tem sua formação Católica, porém, com influência africana, indígena e negra escravizada a princípio, além, obviamente, da grande interferência europeia católica catequizadora. Nesse patamar, Rosafa (2008), acrescenta que, durante a escravidão, os negros eram repreendidos quando tentavam cultuar seus deuses, às vezes eram punidos pelos seus donos e, em algumas situações, pela própria Igreja, pois

Uma das principais alternativas para manifestarem seu contato com o "divino" estava em, apoiados pelo colono e a sua igreja, aproveitar as festas cristãs, forjando uma devoção aos santos católicos quando na realidade, estavam sintonizados aos seus deuses e ancestrais africanos. (ROSAFA, 2008, p. 29)

E foi a partir dessa junção dos deuses africanos com os santos católicos, que começou a ocorrer uma política de trocas entre os elementos sagrados de uma e/ou outra religião.

Ortiz afirma que o "[...] Brasil se constituiu através da fusão de três raças fundamentais: o branco, o negro e o índio" (ORTIZ, 2012 apud JARDIM, 2017, p. 85), evidenciando que o país é formado por sincretismos, não só em termos religiosos, mas do povo como um todo quanto à ampla mistura de raças. Desta forma, o próprio sincretismo religioso é um patrimônio cultural e imaterial, já que é a expressão de costumes afrobrasileiros, reúne elementos de diversas religiões em uma só (MORAES, 2014). Logo, ao ser definida como genuinamente brasileira, a Umbanda se constitui da miscigenação, que é a junção de vários povos, relacionando-se a também junção de várias religiões. E essa conjugação de santos católicos, Orixás e divindades indígenas, torna-se fundamental para a formação da Umbanda. Importa ressaltar que o Kardecismo também fez parte da formação dessa nova religião, pois a base dos cultos umbandistas está na possessão e em transes, muito presentes nessa linha de Kardec, porém, de forma mais reservada. 
Nesse mesmo segmento, Valente (1955), afirma que o sincretismo é a tentativa de resolução de problemas culturais, que tem como característica o "status" no sentido de ocupar uma posição dentro da cultura, dado que,

O sincretismo se caracteriza fundamentalmente por uma intermistura de elementos culturais. Uma íntima interfusão, uma verdadeira simbiose, em alguns casos, entre os componentes das culturas que se põem em contacto. Simbiose que dá em resultado uma fisionomia cultural nova, na qual se associam e se combinam, em maior ou menor proporção, as marcas características das culturas originárias. (VALENTE, 1955, p. 42)

O mesmo teórico postula ainda, o que já fora mencionado anteriormente sobre o período da escravidão, quanto à questão dos deuses africanos adorados pelos negros escravizados, a relação desses deuses com os santos da Igreja Católica e a cristianização do negro no Brasil; e diante desse contexto, é fundamental o resgate de elementos que fazem parte desse sincretismo.

\subsection{A Umbanda como patrimônio cultural imaterial}

No combate à massificação, à homogeneização e à padronização cultural, decorrentes da globalização cultural, deve-se resgatar a diversidade de recursos simbólicos que origina a identidade cultural, especialmente, aos grupos minoritários, o que, em verdade, estabelece como patrimônio imaterial, a forma de se preservar e proteger os registros daquilo que foi mantido pela tradição e que identifica um grupo. Outrossim, patrimônios são bens culturais materiais e imateriais reconhecidos como Patrimônio Cultural do Brasil, e transmitidos de geração em geração, geram uma continuidade, promovendo o respeito à diversidade cultural. Nesse viés, a UNESCO

considera que uma das formas mais eficazes de preservar o patrimônio imaterial é garantir que os portadores desse patrimônio possam continuar produzindo-o e transmitindo-o. Assim, a Organização estimula os países a criarem um sistema permanente de identificação de pessoas (artistas, artesãos etc.) que encarnam, no grau máximo, as habilidades e técnicas necessárias para a manifestação de certos aspectos da vida cultural de um povo e a manutenção de seu patrimônio cultural material. (UNESCO, 2014, p. 1).

Na Constituição de 1988, há uma concepção ampla de patrimônio cultural; Londres (2007), elenca em seu texto, "O patrimônio histórico na sociedade contemporânea:"

I- $\quad$ As formas de expressão;

II- $\quad$ Os modos de criar, fazer e viver; 


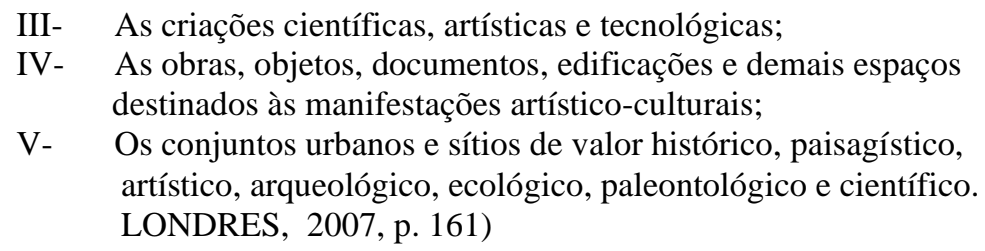

O Instituto do Patrimônio Histórico e Artístico Nacional (IPHAN), a partir da década de 1970, determina que o patrimônio não se basta apenas aos monumentos reconhecidos pela elite, mas também, a manifestações culturais dos índios, negros, imigrantes; em outras palavras, das classes mais populares, passando a serem entendidas como referências culturais, que enfatizam a diversidade de produção e o valor de cada sujeito social como produtor de bens culturais. (BALDIOTTI; SANTANA, 2020)

O decreto $n^{\circ} 42557 / 16$ que declara patrimônio cultural de natureza imaterial a Umbanda, cria também, o cadastro dos terreiros umbandistas, considerando que todos os elementos sejam preservados e disseminados, como os que se seguem no decorrer do texto.

A defumação é uma forma de purificar o ambiente e quem nele se encontra. Com o intuito de "limpar" toda a ambiência de "qualquer 'carga' ou 'carrego' que tenha ficado de sessões anteriores ou que tenham adentrado aquele espaço antes do início dos trabalhos espirituais" (CAMPOS, 2017, p. 15). Esse ato de defumar, segundo Douglas Rainho, no texto "Magia de Umbanda: fumaça, defumação e fumo", promove a conexão com a natureza, pois possui ervas de acordo com a intenção da limpeza, que podem ser usadas para descarregar ou para prevenir contra as energias negativas vindas de fora. Não esquecendo que, é também, uma delimitação do espaço sagrado, pois, dependendo das ervas e da localização do terreiro, pode se sentir o cheiro e identificar que há um espaço religioso por perto.

Nas sessões de Umbanda, a defumação é um fundamento importante, pois prepara o ambiente, os médiuns e os visitantes para o "trabalho"; toda energia negativa é jogada fora, assim as vibrações saem do plano espiritual e as entidades podem trabalhar. Essa purificação serve, ainda, para atrair boas energias e vibrações, de acordo com o que está sendo queimado e para a purificação, é necessário carvão em brasa e ervas secas.

Nesta mesma direção, existem as ervas que são usadas além da defumação, as que são utilizadas nos terreiros logo no início das manifestações dos guias espirituais (orixás e entidades), que aconselham os visitantes a se banharem com as essas ervas para se fortalecerem espiritualmente ou descarregarem energias negativas.

Os guias espirituais carregam conhecimento de encarnações anteriores, sobre ervas e seus usos, entendendo para que servem cada tipo e como usá-las como remédios para as dores 
da alma. A partir desse conceito, cita-se também o seu uso para o "batizado" dos filhos de um terreiro umbandista. (SARACENI, 2012, p. 163).

O Amaci, que funciona como um batizado, é um fundamento muito importante na Umbanda; é a lavagem da cabeça de um médium, com água e ervas específicas, de acordo com cada casa. Este fundamento foi recomendado pelos guias espirituais, desde o início da religião e indica-se ao médium que fará a lavagem de coroa (cabeça), faça um resguardo antes, não mantendo relações sexuais com seus cônjuges e/ou parceiros, não ingerindo carne vermelha e evitando festas e bebidas alcóolicas. No dia seguinte ao Amaci, o resguardo continua. Este ritual é realizado somente uma vez no ano, e de acordo com Saraceni (2012),

O amaci usa ervas específicas dos orixás, curtidas após sererm maceradas e que ficam diante do altar recebendo também a irradiação das divindades e, por meio dessas irradiações, elas vão recebendo um axé específico que, quando derramadas sobre a coroa (cabeça) dos filhos da casa, eles passam por uma energização que beneficia posteriormente a incorporação dos seus guias espirituais. (SARACENI, 2012, p. 164).

Uma observação importante que Saraceni (2012) faz a este respeito é que, quando uma pessoa já foi iniciada no Candomblé e passa a ser umbandista, a iniciação feita não precisa ser refeita, pois a vibração do Orixá é a mesma em ambas as religiões.

Outro bem material nos terreiros umbandistas são os atabaques, que são tocados pelos ogãs. Os ogãs são homens que não entram em transe. Eles são responsáveis pela música utilizada nas sessões. Porém, de acordo com André Luiz Almeida, em alguns terreiros, os ogãs " [...] também auxiliam em outras funções importantes da casa, como o sacrifício animal (nos terreiros de Candomblé), colheita de ervas, cozimento de oferendas, auxílio às mães e pais de santo" (ALMEIDA, 2013, p. 51). Acredita-se que, se um ogã incorporar, entrar em transe mediúnico, ele pode quebrar a vibração fluídica da sessão espiritual, pois o ponto cantado, entoado por eles, auxilia na vibração com as entidades. Na Umbanda, tocar o atabaque é muito mais que um exercício cerebral e motor. É uma “[...] afirmação de devoção, construída através da participação nos ritos sagrados realizados nos terreiros em diálogo com o sentimento de pertencimento ao grupo" (ALMEIDA, 2013, p. 51).

Eles acreditam que "o som dos atabaques e nos movimentos da dança é que 'chegam os santos...as entidades'. Na maioria dos terreiros de Umbanda, as músicas antecedem os ritos de incorporação dos médiuns." (QUINTO, 2018, p. 1)

O médium faz o papel de ligar o céu e a terra e por isso, ocupa uma função importante nos terreiros. Para o pesquisador Gregório José Pereira de Queiroz, "Na Umbanda, um 
médium pode incorporar um 'santo', ou orixá, que é uma divindade africana, ou uma 'entidade', que é um ente que já viveu em nosso plano.” (QUINTO, 2018, p. 1).

A prática do culto religioso leva, também, à aprendizagem da doutrina umbandista com seus fundamentos, tanto para médiuns, quanto para visitantes do terreiro. Sendo que, cada casa ou terreiro escolhe seus pontos e orações que devem ser respeitados, assim, o culto coletivo objetiva desenvolver a reflexão e a religiosidade, inspirando pensamentos pessoais. Nesse cenário, há também os cultos consagratórios, que utilizam e consagram imagens, talismãs, ervas e outros elementos, que possuam energia e valor terapêutico na cura e desobsessões. (BALDIOTTI; SANTANA, 2020).

Guias são colares usados pelos médiuns para harmonizar as energias recebidas a todo o tempo. "Os guias espirituais, quando consagram colares para seus médiuns ou para os consulentes, para serem usados como protetores, imantam esses colares com uma vibração específica que os tornam repulsores ou anuladores de projeções energéticas negativas [...]" (SARACENI, 2013, p. 34). A utilização desses colares é visto pelos umbandistas como um dos fundamentos mágicos da religião, pois são consagrados pelo chefe do terreiro e pelas entidades, e após esse protocolo, estarão prontas para uso; e dessa forma, os médiuns se sentem protegidos dos males presentes no caminho. (BALDIOTTI; SANTANA, 2020).

As entidades trabalham diretamente com os médiuns e os consulentes (fiéis que visitam os terreiros). Elas "[...] situam-se a meio caminho entre a concepção dos deuses africanos do Candomblé e os espíritos dos mortos dos Kardecistas" (BARROS, 2013, p. 2); podem ser qualificadas como espíritos de mortos, e suas características pessoais são substituídas por um estereótipo, ou seja, não é a evocação de um indivíduo que já partiu, mas de uma representação de modelos sociais expressos nos médiuns; é por meio da possessão que as entidades se manifestam no corpo do médium, assim, o mesmo assume os trejeitos dessa entidade. Essa possessão permite o encontro do coletivo com o individual, pois valoriza a participação do médium (individual) no ritual coletivo. (BALDIOTTI; SANTANA, 2020). Como sendo entidades superiores, os Orixás têm a função de comandar sua linha e, quando necessário, participam de trabalhos em terreiros de Umbanda. Eles não "baixam" sempre nos terreiros, mas ficam na vigília, sempre de guarda, caso necessitem de sua presença. Para Rosileide Silva, Orixás são “[...] divindades que se relacionam e personificam as forças da natureza" (SILVA, 2018, p. 129). Na visão dos umbandistas, os Orixás são espíritos que representam a natureza, como por exemplo, a força das águas representada por Oxum, a sabedoria e destreza dos índios, por Oxóssi e a grandeza do mar por Iemanjá. 
Seguindo esse raciocínio, existem as sete linhas da Umbanda, que norteiam todo o trabalho dentro dos terreiros e ajudam a separar e classificar as entidades de acordo com suas características,

\begin{abstract}
O universo umbandista não é estático, as linhas formam redes de comunicação onde circulam as informações divinas. Cada linha é composta por um guardião e seis chefes de legiões, denominados intermediários diretos, que asseguram a intercomunicação sagrada com as demais vibrações. (ORTIZ, 1991, p. 85, grifo do autor).
\end{abstract}

Ainda nesse campo de pensamento, há também, as oferendas, que surgiram nos primórdios da civilização e duram até hoje. Traçando um paralelo em meio a contextualizações, os povos antigos não tinham acesso à medicina de hoje; para curar doenças, eles faziam oferendas aos deuses e divindades, acreditando que seriam curados. Todavia, a ação de ofertar era inspirada pelos próprios espíritos; como se eles, incorporados, conduzissem o ritual, e de acordo com Saraceni (2012, p. 238), isso foi considerado superstição durante muito tempo. Normalmente, as oferendas eram e ainda são deixadas em lugares abertos, na natureza, pelo fato de pessoas que terem o dom da vidência e clarividência, sendo orientadas diretamente pelas divindades para afastar surtos e doenças contagiosas, e até mesmo um evento climático catastrófico. Nesse sentido, Saraceni (2012) postula que,

\begin{abstract}
As forças e os poderes naturais estão assentadas no plano natural da Criação e muito podem fazer por nós se soubermos nos dirigir até seus santuários naturais, se soubermos como interagir espiritualmente com suas forças espirituais, constituídas por seres da natureza, e se soubermos como nos servir dos seus poderes, irradiados o tempo todo por seus manifestadores naturais e condensáveis em determinados elementos mágicos ou possuidores do axé das Divindades Naturais. (SARACENI, 2012, p. 238).
\end{abstract}

Isto exposto, as oferendas podem variar de significados, como por exemplo, servem para agradecer, pedir ajuda, descarregar energias, purificar ou simplesmente, agradar ao Orixá. Em continuação, Saraceni (2012) discorre com propriedade sobre os pontos riscados, ao estabelecer que,

O uso de símbolos no chão é um fundamento mágico da religião de Umbanda, magística por excelência. São os "pontos riscados", por meio dos quais as entidades espirituais traçam "espaços mágicos", abrem vórtices de energia e campo de vibração para limpeza, descarga, cortes de energia. (SARACENI, 2012, p. 9).

Os pontos riscados são desenhos feitos pelas entidades no chão do terreiro, para auxiliar nos trabalhos, e para riscá-los, utilizam-se de giz mineral branco, arredondado, 
chamado "Pemba". A primeira entidade que riscou um ponto foi, segundo Pereira (2012, p. 119), o Caboclo índio Quebra-barreiras, riscando conforme sua linha de trabalho. O autor afirma que "[...] os pontos riscados são, nesse caso, instrumentos que alimentam o universo simbólico da Umbanda" (PEREIRA, 2012, p. 119). Através do ponto riscado, o médium obtém uma segurança maior para identificar a origem da entidade, pois cada entidade tem seu jeito próprio e seus apetrechos, que são, normalmente, representados nos desenhos, como é o caso das flechas no ponto de um Caboclo. Importante salientar, que a mesma entidade pode riscar vários pontos de acordo com a linha de trabalho que for utilizada no terreiro onde ela se encontra.

Para o teórico Solera (2014), os pontos riscados podem ser feitos no chão, paredes ou em tábuas de madeira, com o mesmo giz citado anteriormente, para atrair ou repulsar forças positivas ou negativas e, seguindo esse viés, adeptos umbandistas também acreditam que os pontos riscados "[...] são utilizados como base para a magia simbólica dos Orixás e na confecção de objetos de poder, os chamados talismãs, sinetes astrais, escudos mágicos e outros" (SOLERA, 2014, p. 36).

Os pontos riscados são ordens escritas (grafia, celeste), de UM a VÁRIOS setores com a identidade de quem pode e ESTÁ ORDENADO para isso. É pelo ponto riscado que as entidades se identificam por completo nos aparelhos de incorporação, principalmente nos semiconscientes, pois seus subconscientes, nesses fundamentos, não influem, simplesmente porque não conhecem seus valores. (SILVA, 1979 apud SOLERA, 2014, p. 37).

Em síntese, o ponto riscado na Umbanda é caracterizado, basicamente, por flechas, chaves e raízes, e fora mencionado suscintamente, por conta de sua importância nos terreiros, porém, no presente, esses aspectos não serão aprofundados, já que o foco da dissertação fixa em ponto cantado.

Em se tratando de terreiro, define-se como o espaço onde acontecem os trabalhos de incorporações e transes. Muitas vezes, esse local funciona em casas, quintais improvisados ou pequenos galpões alugados, entretanto, segundo Muniz Sodré, no livro "O terreiro e a Cidade”, este espaço sagrado, geralmente, existe dentro de quem tem a força, não precisando, necessariamente, ser um lugar físico. Cada casa umbandista organiza seu espaço conforme sua vontade e de suas entidades que ali vão trabalhar.

Tendo como exemplo a Tenda Espírita Umbandista de Santa Barbara, localizada em Teresina, a autora Ariany Maria Farias de Souza, afirma que, 


\begin{abstract}
a parte que mais nos chama a atenção dentro deste cenário é o barracão onde estão dispostos o maior número de santos católicos e imagens de orixás da umbanda, todos em cima de um grande altar que fica centralizado neste espaço. No meio deste altar está a imagem de Jesus Cristo e ao seu lado temos: Iemanjá, Cosme e Damiao, Xangô, Oxóssi, São Jorge, Pomba Gira e outros. [...] A parte externa da casa é composta por um grande número de arvores e de mata em um terreno de chão batido. (SOUZA, 2013, p. 2)
\end{abstract}

Os terreiros, em geral, de acordo com a região e algumas variações, compõem-se de uma entrada, ao lado esquerdo se encontra a tronqueira, que é o local onde os Exus são saudados, além de manter o mal afastado; do lado direito, a casa de Preto Velho, também para saudação e despedida dos fiéis. Encontram-se, também, do lado de fora, as plantas, principalmente samambaias de chão, espadas de Ogum (São Jorge), espadas de Iansã (Santa Bárbara), arruda e guiné, que são as ervas utilizadas em muitos trabalhos e banhos, recomendados pelas entidades (SOUZA, 2013).

Ao se adentrar no local, observa-se um altar com muitas imagens dispostas de forma organizada, de acordo com uma hierarquia, que os umbandistas acreditam ser a correta. $\mathrm{O}$ teto é, quase sempre, enfeitado com bandeirinhas, como as de festa junina, colocadas em homenagem às crianças no dia de São Cosme e São Damião e não mais retiradas, somente renovadas no ano seguinte no mesmo período. Do lado esquerdo do altar, estão os atabaques, instrumentos de percussão tocados pelos ogãs, em um ritmo que dura a sessão inteira. $O$ espaço das imagens, atabaques e médiuns trabalhadores é separado dos consulentes (visitantes), em alguns terreiros por muretas, em outros por plantas, cordas, de acordo com os recursos do pai de santo e a contribuição dos filhos da casa. Ortiz (1991), no livro "A morte branca do feiticeiro negro", fala sobre os terreiros e suas disposições, utilizando como exemplo, o terreiro da Vovó Maria Conga em Realengo, no Rio de Janeiro, e descreve com propriedade o embranquecimento e o empretecimento:

A tenda reúne uma série de manchas afro-brasileiras, pois sua mãe-de-santo iniciouse primeiramente no Candomblé, e só bem mais tarde começou a frequentar um ritual situado justamente no pólo oposto do continum: a Tenda Mirim. Pode-se dizer neste caso que no nível da pessoa do chefe do culto situa-se a dupla origem da Umbanda: o embranquecimento das práticas afro-brasileiras, e o escurescimento de uma ialorixá branca, em busca da tradição negra. (ORTIZ, 1991, p. 98).

De certa forma, os terreiros de Umbanda, geralmente, são mais simples que os de Candomblé, do qual tiveram muita inspiração; especificamente esse, segundo Ortiz (1991), há areia no chão, pois a madrinha do terreiro é Iemanjá, a rainha do mar. Normalmente, salões ou salas umbandistas configuram uma cruz, reforçando, também, a influência do catolicismo, e 
apesar de o sagrado estar presente nos terreiros, o profano aparece no formato do Exu, "[...] aquele que guarda a entrada do terreiro contra os males do mundo [...]" (ORTIZ, 1991, p. 99). A sala de culto é grande, abrigando muitas pessoas, separando-as por sexo, além de separar dos trabalhadores da casa, por uma mureta. Esta separação simboliza o sagrado e o profano, sendo que o sagrado se refere aos trabalhadores e o profano aos visitantes, metaforicamente falando.

\section{Conclusões}

Os principais elementos da Umbanda que a levaram a ser reconhecida como patrimônio cultural imaterial delineiam o sincretismo religioso, que é amplamente discutido por vários autores, sendo considerado uma mistura de várias crenças dentro de uma só, já que se constitui de elementos do Catolicismo, do Kardecismo, do Candomblé e das tradições dos indígenas, utilizando-se de rituais e objetos destas religiões. Além disso, a identidade negra é resgatada na Umbanda através das músicas, com suas peculiaridades como os transes e possessões nas sessões, que podem ser definidas como a força espiritual presente nos terreiros e suas entidades que merecem todo respeito.

Alguns elementos do terreiro umbandista, que fazem parte dos rituais são: a defumação utilizada para limpar o ambiente de energias negativas; as ervas para curar e trabalhar desenvolvimentos com os fiéis da casa; atabaques, instrumentos de percussão usados para dar ritmo às músicas; as giras, que podem ser de assistência e de desenvolvimento dos fiéis do terreiro; as guias, colares usados pelos médiuns, para auxiliar dando força e protegendo durante os trabalhos; oferendas, em que os devotos oferecem comidas e presentes às suas entidades de devoção; e pontos riscados usados em trabalhos de desobsessão, além de identificar a entidade presente no terreiro e o terreiro em si, que é o espaço sagrado onde todos os rituais acontecem.

Ao considerar a Umbanda como patrimônio cultural de natureza imaterial, o Estado, cria condições para através do discurso da legalidade, resgatar toda a tradição oral experienciado em cada terreiro. A maioria das pessoas que professa qualquer credo, normalmente acredita em elementos de outras religiões, sem causar estranheza e dessa forma, a Umbanda expressa de uma forma singular esse sincretismo religioso, encarado como natural na expressão religiosa brasileira.

\section{Referências}


ALMEIDA, A. L. M. A música sagrada dos ogãs no terreiro de Umbanda "Ogum Beira Mar e Vovó Maria Conga" da cidade de Goiânia de Itaberaí: representações e identidades, 2013. 127f. Dissertação (Mestrado em Música). Escola de Música e Artes Cênicas da Universidade Federal de Goiás, Goiânia, 2013.

BALDIOTTI, G. R. C. Da vibração ao transe: uma apresentação das entidades espirituais nos pontos cantados da Umbanda. $94 \mathrm{f}$. Dissertação (Mestrado)- Universidade Vale do Rio Verde, Três Corações, 2020.

BALDIOTTI, G. R. C.; SANTANA, T. R. A umbanda como patrimônio cultural material e imaterial. Revista África e Africanidades, [S. 1.], Ano XII, n. 33, p. 1-13, fev. 2020.

BARROS, S. C. As entidades 'brasileiras' da umbanda e as faces inconfessado Brasil. XXVII Simpósio Nacional de História, Natal, 2013.

CAMPOS, L. R. de. Muitas linhas de um mesmo riscado: a umbanda das zonas de contato. 2017. 105 f. Dissertação (Mestrado em Ciência da Religião). Pontifícia Universidade Católica de São Paulo, 2017.

CASTRO, J. G. A formação de uma igreja sincrética: Igreja do Nazareno do Cabral. 67 f. Dissertação (Mestrado em Ciências da Religião)- Universidade Presbiteriana Mackenzie, São Paulo, 2013.

JARDIM, T. Umbanda: História, cultura e resistência. Rio de Janeiro: Universidade Federal do Estado do Rio de Janeiro, 2017. Disponível em:

http://www.unirio.br/unirio/cchs/ess/tccs/tcc-tatiana-jardim-1. Acesso em: 20 out. 2020.

LONDRES, C. O patrimônio histórico na sociedade contemporânea. Escritos Revista da Fundação Casa de Rui Barbosa, Rio de Janeiro, ano 1, n 1, p. 159- 171, 2007.

MORAIS, M. A. O sincretismo religioso como elemento legitimador da umbanda: Uma Breve Reflexão a partir da obra Casa Grande e Senzala. Revista Continentes (UFRRJ), Rio de Janeiro, ano 3, n.4, p.180-200, 2014

NASCIMENTO, A. A. S. Candomblé e Umbanda: práticas religiosas da identidade negra no Brasil. RBSE, [S. 1.], v. 9, n. 27, p. 923-944, 2010.

ORGANIZAÇÃO DAS NAÇÕES UNIDAS PARA EDUCAÇÃO, CIÊNCIA E CULTURA (UNESCO). Patrimônio cultural imaterial. 2017. Disponível em:

http://www.unesco.org/new/pt/brasilia/culture/world-heritage/intangible-heritage/. Acesso em: 31 out. 2020.

ORTIZ, R. A morte branca do feiticeiro negro. São Paulo: Brasiliense, 1991

PEREIRA, L. J. A. A umbanda em fortaleza: análise dos significados presentes nos pontos cantados e riscados nos Rituais religiosos. 2012 142f. (Dissertação de Mestrado em Educação)- Universidade Federal do Ceará, Fortaleza, 2012.

PRANDI, R. O Brasil com axé: Candomblé e Umbanda no mercado religioso. 2004. 
QUINTO, A. C. Estudo destaca papel central da música nos ritos de incorporação da Umbanda. Jornal da USP, 3 jul. 2018. https://jornal.usp.br/ciencias/ciencias-humanas/estudodestaca-papel-central-da-musica-nos-ritos-de-incorporacao-da-

umbanda/\#: :text=\%E2\%80\%9CNa\%20Umbanda $\% 2 \mathrm{C} \% 20 \mathrm{um} \% 20 \mathrm{~m} \% \mathrm{C} 3 \%$ A 9 dium $\% 20$ pod e,em\%20nosso\%20plano\%E2\%80\%9D \%2C\%20descreve.\&text=A\%20m\%C3\%BAsica\%20e $\% 20 \mathrm{a} \% 20$ express $\% \mathrm{C} 3 \% \mathrm{~A} 3 \mathrm{o}$,forma $\% 2 \mathrm{C} \% 20 \mathrm{mas} \% 20 \mathrm{n} \% \mathrm{C} 3 \% \mathrm{~A} 3 \mathrm{o} \% 20$ nos $\% 20$ objetivos.

Acesso em: 10 dez. 2020

RIO DE JANEIRO. Decreto $n^{\circ} 42557$ de 07 de novembro de 2016.

Declara patrimônio cultural de natureza imaterial a umbanda e cria o cadastro dos terreiros de umbanda. 2016. Disponível em:

http://www.rio.rj.gov.br/dlstatic/10112/4368015/4176955/40DECRETO42557CadastrodosTe rreirosdeUmbanda08112016.pdf. Acesso em: 10 dez. 2020

ROSAFA, W. Terreiro de Umbanda Mártir de São Sebastião: registros de patrimônio imaterial. 2008. 129 f. (Mestrado Profissional em Gestão do Patrimônio Cultural)Universidade Católica de Goiás, Goiânia, 2008.

ROSSETO, S. C. Religiões de matriz africana / inclusão ou exclusão na disciplina de ensino religioso? 2016. 237f. Dissertação (Mestrado Ciências das Religiões) - Faculdade Unida da Vitória, Vitória, 2016.

SARACENI, R. Fundamentos doutrinários de Umbanda. São Paulo, Madras, 2012.

SILVA, R. Ritual e performance feminina na aldeia dos orixás. Maceio: UFAL, 2018. Disponível em:

http://www.repositorio.ufal.br/bitstream/riufal/4833/1/Ritual\%20e\%20performance $\% 20 \mathrm{femin}$ ina\%20na\%20Aldeia\%20dos\%200rix\%C3\%A1s.pdf. Acesso em: 11 dez. 2020

SOLERA, O. O. O. A magia do ponto riscado na Umbanda Esotérica. 95 f. Dissertação (Mestrado Ciências da Religião)- Pontifícia Universidade Católica de São Paulo, São Paulo, 2014.

SOUZA, A. M. F. Um encontro dialógico na Tenda Espírita Umbandista de Santa Barbara em Teresina-PI. $1^{\circ}$ Simpósio Internacional da ABHR, São Paulo, 2013.

VALENTE, W. Sincretismo religioso afro-brasileiro. São Paulo: Companhia Editora Nacional, 1955. 